\title{
Community-based Waste Management Programs: Case Study in Maharagama Urban Council Area
}

\author{
Wijayawardhana W.P.M.A. ${ }^{{ }^{*}}$, Athapattu B.C.L. ${ }^{2}$ and Karunarathna A.K. ${ }^{3}$ \\ ${ }^{I}$ Department of Local Government, Western Provincial Council, Sri Lanka, \\ ${ }^{2}$ Department of Civil Engineering, The Open University of Sri Lanka, \\ ${ }^{3}$ Department of Agricultural Engineering, University of Peradeniya, Sri Lanka \\ *anuradha.wpm@gmail.com
}

\begin{abstract}
Waste disposal and management are common issues in urban and rural areas of Sri Lanka. Limited resources at Local Authorities for management and inappropriate dumping aggravate those issues. However, in a broad perspective, every person in the society is a potential generator of waste and thus a stakeholder in the issue. Many of the formal interventions over the past several years for community based waste management Programmes (CBWMP) unfortunately failed to meet expected benefits. The Maharagama Urban Council (MUC) is an example where in-situ bin composting was introduced yet no information is available on its success. Therefore, this research is focused to explore feasibility and effectiveness of CBWMP and how it affects source reduction of waste generation in MUC area.
\end{abstract}

This research used a combination of quantitative and qualitative methodologies. A questionnaire survey was designed to identify the income levels, social attitudes about the waste management, attitudes of waste segregation, land extent, waste management knowledge, reasons for failures of existing organic waste management methods. Alternatively, "Takakura" composting method was introduced as a pilot study for 15 households and 3 institutions as a mean of in-situ organic waste management process and evaluated its sustainability. The Takakura method uses native organisms for composting-cultured and fermented from locally available materials such as fresh fruits, vegetable peels, soy source, brown sugar, curd and mushroom rice bran and rice husks.

The findings of the questionnaire revealed that a majority of households in the MUC are concerned about waste management and yet sorting of waste is not adopted by many. The practice of reuse, recycle and reduce (3Rs) concepts are also low in MUC area. People were of the opinion that it is not possible to reduce the volume of waste generation. The pilot programme of the Takakura composting method showed reduction of $40 \%$ organic waste generation which was also a fast, easy and economic method. Consequently, the new adaptation to Takakura composting can improve environmental hygiene, eliminate of foul odors and reduce emission of methane gas. Further, it is important that the Central Government support the local authorities in implementing such projects through provision of financial support for the household composting and institutional mini composting centers, promoting its usage in urban agriculture, and providing other financial and political incentives to reduce waste generation. In perspective, this type of in-situ waste management strategies will always improve people's living standards and opt for a green life in a greener city.

Keywords: Community based waste management programmes, Takakura composting method, Maharagama Urban Council area

Proceedings of the International Forestry and Environment Symposium 2016, Department of Forestry and Environmental Science, University of Sri Jayewardenepura, Sri Lanka. 